Revista de Literatura, História e Memória

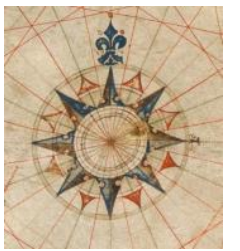

Seção: Pesquisa em Letras no contexto Latino-americano e Literatura, Ensino e Cultura

ISSN 1983-1498

VOL. 16 - No 27 - 2020

U N I O E S T E / CA S C A V E L - p. 262-277

\title{
LINGUAGEM E RESISTENNCIA EM MULHERES DE CINZAS, DE MIA COUTO E AMERICANAH, DE CHIMAMANDA ADICHIE
}

\section{Language and resistance in Mulheres de cinzas, of Mia Couto and Americanah, of Chimamanda Adichie}

\author{
Cleonice Alves Lopes Flois ${ }^{1}$
}

RESUMO: Pelo viés dos Estudos Comparados e das teorias PósColoniais abordo a linguagem como ferramenta de resistência e de poder cujo discurso atua fazendo com que as representações ideológicas se materializem. Nas narrativas Americanah (2014), da nigeriana Chimamanda Adichie e Mulheres de Cinzas (2015), do moçambicano Mia Couto a linguagem é apresentada como um refúgio de vozes de um poderio discursivo de grande valor cuja utilização permite que grupos minoritários venham a ter espaço para ser percebidos e, possivelmente, ouvidos. Adichie e Couto fazem aparecer, na linguagem das personagens, expressões próprias, palavras ou frases da língua de tribos nativas que compõem o enredo. Ocorrem, nessa escrita, processos de hibridismos em que uma língua, a do negro, do colonizado, se enleia a outra passando, assim, a ocupar um espaço. Percebe-se então, que a linguagem expressa uma identidade cultural sendo representada por meio de outras narrativas que se inserem na história tecendo assim uma escritura dupla.

PALAVRAS-CHAVE: Linguagem; Resistência; Poder; Escritura dupla; Identidade Cultural.

ABSTRACT: Through the bias of Comparative Studies and Postcolonial theories I approach language as a tool of resistance and power whose discourse acts by making ideological representations materialize. In the narratives Americanah (2014), by Nigerian Chimamanda Adichie and Mulheres de Cinzas (2015), by Mozambican Mia Couto the language is presented as a refuge of voices of a great value discursive power whose use allows minority groups to have oportunity for be perceived and possibly heard. Adichie and Couto make appear, in the language of the personages, own expressions, words or phrases of the language of native tribes that compose the plot. In this writing, processes of hybridity occur in which one language, that of the black people, of the colonized, becomes entwined with another, thus occupying a space. It is then realized that language expresses a cultural identity being represented through other narratives that are inserted in history weaving so a double writing.

KEYWORDS: Language; Power; Resistance; Double writing; Cultural Identity.

\section{INTRODUÇÃO}

A pesquisa tem como proposta apresentar as imagens poéticas dos processos identitários híbridos, da linguagem em deslocamentos e suas tentativas de ultrapassar fronteiras bem como da resistência e subversão que constituem o tecido narrativo das obras.

\footnotetext{
${ }^{1}$ Doutoranda em Letras pela Universidade Estadual do Oeste do Paraná (UNIOESTE). Mestra pela mesma instituição (2018). Membro do Grupo de Pesquisas Confluências da Ficção, História e Memória na Literatura e nas Diversas Linguagens. Mediadora do Clube de Leitura Leia Mulheres Toledo/PR. Membro do Mulherio das Letras nacional e do Paraná.
} 
As narrativas Americanah (2014), da escritora nigeriana Chimamanda Ngozi Adichie e Mulheres de Cinzas (2015), do escritor moçambicano Mia Couto são obras que compõem a literatura africana analisadas nesta pesquisa sob o viés da Literatura Comparada e sob o enfoque do Pós-Colonialismo, cada uma em diálogo com o seu espaço enunciativo.

Apresento inicialmente Americanah, e suas personagens principais para tratar da importância da linguagem, uma vez que a autora mostra, por meio de suas personagens, como a linguagem pode ser utilizada como instrumento de subversão diante de sociedades opressivas e colonizantes. É abordado também como uma pessoa pertencente à etnia Igbo vê os países para os quais imigra e a própria Nigéria, fato que ocorre com algumas personagens, inclusive a protagonista Ifemelu, criando uma representação mais completa dos aspectos da cultura nigeriana.

Na sequência falo sobre Mulheres de Cinzas e a importância da linguagem para as personagens da narrativa que a utilizam como ferramenta de poder diante das práticas eurocêntricas de racismo e machismo. A língua, como um dos instrumentos por meio dos quais os homens se expressam, é carregada por um discurso e apresenta como uma das suas características constantes o fato de ser ideológica, posicionamento encontrado na narrativa que se utiliza do hibridismo linguístico para tecer uma obra rica de diversidades nas representações poéticas e no poderio discursivo.

\section{A LÍNGUA COMO FATOR DE SUBVERSÃO EM AMERICANAH}

O romance Americanah tem início com uma história de amor entre a jovem Ifemelu e o jovem Obinze que acaba sendo interrompida pela ida dela aos Estados Unidos para dar continuidade aos estudos que não pode fazer na Nigéria devido ao caos pelo qual o país estava passando sob um regime militar.

Primeiro, Ifemelu vai aos Estados Unidos, aonde uma tia já está morando, mais tarde é a vez de Obinze imigrar, mesmo que ilegalmente, para a Inglaterra. Ao apresentar, por meio da literatura, a trajetória desses dois jovens que saem da Nigéria em busca de outras oportunidades, Adichie apresenta, metaforicamente, a história de muitos outros imigrantes que sonham com melhores chances em um país de "primeiro mundo".

Americanah é uma narrativa que problematiza esteticamente questões polêmicas e repletas de tabus como o racismo e o feminismo. A autora compõe um enredo em que há relações complexas entre identidades e cultura, identidades e linguagem e estas, geram deslocamentos em que o indivíduo busca continuamente a si mesmo e ao outro. Nesses 
deslocamentos é construída a alteridade, uma vez que a identidade em construção acontece por meio das relações entre fatores individuais numa interdependência de fatores coletivos.

Nesse espaço há o choque entre a identidade da personagem com a identidade da sociedade na qual está inserida, por exemplo, quando em determinada situação é dita que o sotaque que eles consideram estranho e cheio de afetações linguísticas se tornará o seu desejo em pouco tempo, devido a influência que o social exerce sobre o indivíduo. E assim, a construção da identidade, que não é algo pronto e acabado, é evidenciada na narrativa adichiana como um elemento que não parte apenas do próprio indivíduo, mas da sua relação com o outro representado por elementos como a cultura, a política, a economia que, queira o indivíduo ou não, fazem parte da sua composição atual e da sua relação com o outro neste vasto universo dos processos identitários em constantes deslocamentos.

Adichie destaca em Americanah, as diferentes funções atendidas pelo idioma dominante e pelo idioma Igbo, em particular, na cultura nigeriana. Igbo, o idioma do grupo étnico de Ifemelu, personagem protagonista da narrativa, é falado, principalmente, entre os membros da família. Na juventude, é comum que os jovens sigam para um estilo de vida mais cosmopolita e afastem-se das aldeias de seus antepassados, voltando-se para as influências dos países ocidentais, como ocorreu com Ifemelu e Obinze e com seus amigos de escola, com quem cresceram ouvindo contar sobre suas viagens costumeiras à Europa.

Kayode passava todas as férias na casa dos pais na Inglaterra, que parecia enorme e assustadora nas fotos que Ifemelu já vira. Sua namorada Yinka era como ele - ela também ia à Inglaterra com frequência, morava em Ikoyi e falava com sotaque britânico. (ADICHIE, 2014, p. 64).

A importância dada por eles para países como Inglaterra e Estados Unidos era muito grande, de modo que o seu país ficava em segundo plano. O interesse por quem sairia do país, fosse para viajar, fosse para morar, era comparável ao que dariam se fossem eles mesmos fazendo as malas. Era uma adoração por uma cultura que, mesmo implicitamente, era considerada superior à sua.

Ginika chegou à escola certa manhã com os olhos vermelhos e tristes e disse a Ifemelu: "Papai disse que vamos nos mudar para os Estados Unidos no mês que vem" [...]

Os pais de Ginika já havia algum tempo falavam em pedir demissão da universidade e recomeçar nos Estados Unidos. [...]

$\mathrm{Na}$ escola, os amigos se reuniam em torno dela. Todos queriam levá-la à loja de balas e encontrar com ela depois da escola, como se sua partida iminente a deixasse ainda mais desejável. Ifemelu e Ginika estavam jogando conversa 
fora no corredor durante um intervalo quando Os Caras se uniram a elas: Kayode, Obinze, Ahmed, Emenike e Osahon. "Ginika, você vai para onde nos Estados Unidos?", perguntou Emenike. Ele era fascinado por pessoas que viajavam para o exterior. Depois que Kayode voltou de uma viagem à Suíça com os pais, Emenike se abaixou para acariciar seus sapatos dizendo: "Quero tocá-los, porque eles tocaram a neve".

"Missouri", disse Ginika. "Meu pai arrumou um emprego numa universidade de lá."

"Sua mãe é americana, $a b i$ ? Por isso você tem um passaporte americano?"

"É. Mas a gente não viaja desde que eu estava no terceiro ano do fundamental."

"Um passaporte americano é a coisa mais legal do mundo", disse Kayode. "Eu trocava o meu britânico por um na hora."

"Eu também", concordou Yinka. (ADICHIE, 2014, p. 74-75).

Adichie traz, em Americanah, uma narração que trabalha com a linguagem de forma a evidenciar o uso das duas línguas faladas pela personagem Ifemelu, o Igbo e o inglês. Na Nigéria, terra natal da personagem, há uma política de educação que, na prática, permite o uso da língua materna, como primeiro idioma - principalmente Igbo, Yoruba e Hausa - juntamente com o inglês. Além disso, todos têm acesso à educação bilíngue e é muito comum que os falantes misturem inglês e Igbo em uma mesma frase.

Esse fato é percebido na narrativa em que as personagens mesclam dois idiomas nas interações sem nenhum problema de entendimento na comunicação, como é possível observar nas passagens: "Primeiro passou os olhos pelo e-mail, desejando de imediato que fosse mais longo. Teto, kedu? Espero que tudo esteja bem com o trabalho e a família" (ADICHIE, 2014, p. 26). Também em: "'Querido, kedu ebe I no?" Kosi, sua esposa, sempre iniciava qualquer telefonema para ele com essas palavras. Onde você está?" (ADICHIE, 2014, p. 28). E em: "Veja bem, meu irmão. Você não vai vender por esse preço, ninguém vai comprar. Ife esika kita. A recessão está mordendo todo mundo" (ADICHIE, 2014, p. 490).

Estas expressões só passavam a ser um problema quando um dos falantes queria cortar as relações com a língua materna e usar apenas a língua inglesa, como no caso de Tia Uju, que não queria que Ifemelu falasse em igbo com o sobrinho Dike: "'Por favor, não fale igbo com ele', disse tia Uju. 'Falar duas línguas vai confundi-lo'. 'Como assim, tia? Nós falávamos duas línguas quando éramos crianças.' 'Aqui é a América. É diferente'." (ADICHIE, 2014, p. 120).

É possível observar na fala da personagem Uju, o contraste existente entre o inglês e o Igbo. A língua inglesa, usada como língua oficial e como meio para expressar o pensamento considerado intelectualizado, é considerada diferente por tia Uju, porque estão na América; e o Igbo, língua materna das personagens, - linguagem cheia de metáforas e que assume a função de expressar as emoções nas frases empregadas - não é bem visto por ela, porque 
pode representar inferioridade diante do inglês americano dos Estados Unidos. É o silenciamento cultural presente na imigrante que tenta se adaptar no país que não é o seu.

A questão da linguagem ainda é uma situação não bem resolvida na cultura nigeriana. Existe um sentimento de animosidade na Nigéria após as mortes e a pobreza de numerosas pessoas Igbo causadas pela Guerra de Biafra $^{2}$, que faz com que sintam vergonha da derrota que sofreram. "'É verdade', disse Obinze. 'É triste, é o legado de ser um povo derrotado. Perdemos a Guerra de Biafra e aprendemos a ter vergonha.'" (ADICHIE, 2014, p. 490). Isso pode justificar a não resistência ao abandonar o seu idioma e passar a falar a língua do outro. Essa relação delicada quanto ao idioma nigeriano contemporâneo é evidente na seguinte passagem:

Está vendo, esse é o problema com vocês, igbos. Não tratam de irmão para irmão. É por isso que gosto dos iorubas, eles cuidam uns dos outros. Sabia que outro dia fui ao escritório da Receita Federal perto da minha casa e um homem de lá, um igbo... eu vi o nome dele e falei com ele em igbo, e ele nem me respondeu! Um hausa fala hausa com outro hausa. Um ioruba vê um ioruba em qualquer lugar e fala ioruba. Mas um igbo fala inglês com outro igbo. Fico até surpreso de você estar falando igbo comigo. (ADICHIE, 2014, p. 490).

Torna-se difícil para um país colonizado recuperar sua própria identidade, uma vez que usa o idioma oficial imposto pelo colonizador, de forma que isso reduz a sua língua nativa a um papel secundário. Como em todo idioma, as palavras em Igbo carregam significado e história e a narração destas histórias, bem como de alguns "provérbios é muito importante para o estilo de vida Igbo tradicional e (isso) sempre ajudou a sustentar a língua" ${ }^{3}$ (IFEJIKA, 2016, tradução e grifos meus).

Ifemelu e Obinze fazem uma pequena disputa, logo que se conhecem, na qual trocam provérbios em Igbo, para ver quem sabe mais sobre sua língua materna. As personagens valorizam a sua cultura e manifestam esse sentimento num pequeno jogo para ver quem conhece mais sobre suas raízes.

'Mas aposto que falo igbo melhor que você.'

'Impossível', afirmou Obinze, passando a falar igbo. 'Ama m atu inu. Eu sei

\footnotetext{
2 "A Guerra Civil da Nigéria, também conhecida como Guerra de Biafra, foi um conflito de origem étnica, religiosa e política causado pela ação separatista de uma região ao sudeste da Nigéria do resto do país. Iniciada em 6 de Julho de 1967, a guerra chegou ao fim em 13 de Janeiro de 1970, com a derrota da República de Biafra e um saldo de mais de 2 milhões de mortos." (CHAN, 2007, p. 3).

${ }^{3}$ Storytelling and proverbs are very important to the traditional Igbo way of life, and have always helped to sustain the language.
} 
até os provérbios.'

'Claro. O mais básico, que todo mundo sabe. Um sapo não corre à tarde por nada.'

'Não. Eu conheço provérbios sérios. Akota ife ka ubi, e lee oba. Se algo maior que a fazenda é desenterrado, o celeiro é vendido.'

'Ah, você quer me testar?', perguntou ela, rindo. 'Acho afu adi ako n'akpa dibia. O saco do homem dos remédios tem todo tipo de coisa.'

'Nada mau', disse ele. 'E gbuo dike n'ogu uno, e luo na ogu agu, e lote ya. Se você matar um guerreiro numa briga local, vai se lembrar dele quando estiver lutando contra seus inimigos.'

Trocaram provérbios. Ifemelu só lembrava mais dois quando desistiu, mas Obinze continuava em ponto de bala.

'Como você sabe tudo isso?', perguntou ela, impressionada. "Muitos meninos não querem nem falar igbo, quanto mais saber provérbios.'

'Fico escutando a conversa dos meus tios, só isso. Acho que meu pai gostaria disso.' (ADICHIE, 2014, p. 70).

Ifemelu se impressiona com o conhecimento de Obinze da língua Igbo, mas o rapaz conhecia muito sobre seu grupo étnico, pois se importava em manter viva a sua história por meio da cultura e linguagem do seu povo. Ele demonstrou domínio sobre algo que muitos jovens já estavam deixando de lado e que exigia que ele praticasse falando e interagindo com os membros da sua aldeia para que toda aquela simbologia por trás da linguagem não se perdesse. "'De quanto em quanto tempo você visita sua aldeia?' 'Todo Natal.' 'Só uma vez por ano! Eu vou sempre com a minha mãe, pelo menos cinco vezes por ano'." (ADICHIE, 2014, p. 70). Só essa interação ao visitar a aldeia já ajudava Obinze a manter viva a sua herança familiar. Assim como os provérbios, as metáforas utilizadas na linguagem Igbo, por exemplo, são símbolos desconhecidos para a cultura britânica, ao mesmo tempo que o inglês nigeriano tem sua própria sintaxe diferente do inglês padrão. De acordo com Bhabha:

Torna-se crucial distinguir entre a semelhança e a similitude dos símbolos através de experiências culturais diversas - a literatura, a arte, o ritual musical, a vida, a morte - e da especificidade social de cada uma dessas produções de sentido em sua circulação como signos dentro de locais contextuais e sistemas sociais de valor específicos. (BHABHA, 2005, p. 241).

A hibridação, integração e mistura de símbolos e práticas de diferentes culturas pode levar à assimilação e adaptação das práticas culturais, se não houver uma resistência do próprio sujeito objetificado. Na narrativa, Adichie usa a língua Igbo constantemente na fala de suas personagens e por não haver versões ocidentais de seus nomes, os leitores acabam absorvendo as frases em Igbo na sua forma original. Além disso, nem todas as frases e expressões em Igbo são traduzidas ao longo da narrativa. Para entender o idioma, o leitor 
depende de sugestões no contexto da narrativa ou precisa buscar em dicionários e ferramentas para tradução, onde nem todas as palavras trazem tradução para o português. A expressão 'kedu ebe I no?' tem tradução logo após ser citada, na narrativa. Significa 'Onde você está?'; a expressão 'Ife esika kita', por sua vez, apresenta o significado de 'o amor é muito suave'4, sendo realmente uma expressão, uma vez que a palavra amor não se encaixa no contexto daquela fala das personagens. A expressão 'Dike, I mechago?', dita por Ifemelu a Dike quando ele a chama, não apresenta tradução da palavra mechago, mas tem tradução para $I$, que significa eu em frases afirmativas, mas em uma interrogativa, como é o caso, significa você ${ }^{5}$.

A autora, em entrevista a Brooke Obie, após vencer o National Book Critics Circle Award: Ficção, do ano de 2013, fala acerca do fato da língua materna das personagens, ou seja, a língua do colonizado Igbo estar presente na sua escrita, assim como estava nas suas leituras na adolescência:

Eu sempre tive Igbo [na minha escrita]. E sempre tive conselhos bemintencionados, muitas vezes sobre como os leitores americanos ficarão confusos, ou não entenderão nada. Não me proponho confundir, mas também penso sobre mim como leitora. Cresci lendo livros de todos os lugares e eu não entendia necessariamente todas as coisas - e não precisava entender. Então, penso por mim, o que era mais importante, para a integridade do romance, era que eu capturava o mundo que eu queria capturar, em vez de tentar moldar esse mundo na ideia do que o leitor imaginado iria pensar. (ADICHIE, 2014a, NBCC, Tradução minha). ${ }^{6}$

Adichie lembra uma experiência no início de sua carreira quando foi dito para mudar o cenário de sua história, porque ninguém sabia nada sobre a Nigéria, nem mesmo sua localização geográfica, porque a configuração das suas narrativas poderiam não agradar aos leitores ocidentais. Em resposta, a escritora disse:

O Google é fantástico. 'Se as pessoas estão interessadas, elas podem procurar algo. Lembro-me de pensar: Não me importo se eu for publicada por uma editora muito pequena e apenas dez pessoas lerem, mas será o livro que eu

\footnotetext{
${ }^{4}$ Tradução realizada por meio da ferramenta Google tradutor a partir do idioma Igbo para o idioma português.

${ }^{5}$ Tradução realizada por meio da ferramenta Google tradutor a partir do idioma Igbo para o idioma português.

6 Artigo oriundo da entrevista de Adichie para Brooke Obie, com o título de 'NBCC Fiction Finalist Chimamanda Ngozi Adichie in Conversation with Brooke Obie', em 11 mar. 2014. Disponível em: http://bookcritics.org/blog/archive/nbcc-fiction-finalist-chimamanda-ngozi-adichie-in-conversation-withbrooke. Acesso em: 04 jan. 2017. "I've always had Igbo [in my writing]. And I've always had well-meaning advice, often about how American readers will be confused, or they won't get something. I don't set out to confuse, but I also think about myself as a reader. I grew up reading books from everywhere and I didn't necessarily understand every single thing — and I didn't need to. So, I think for me, what was more important, for the integrity of the novel, was that I capture the world I wanted to capture, rather than to try to mold that world into the idea of what the imagined reader would think." (ADICHIE, 2014a, NBCC).
} 
quero escrever.' E essa foi a minha atitude desde o início. (ADICHIE, 2014a, NBCC, tradução minha). ${ }^{7}$

Assim, Adichie mostra em suas narrativas, por meio de suas personagens, como uma Igbo vê os países para os quais imigra e a própria Nigéria, criando uma representação mais completa dos aspectos da cultura nigeriana.

\section{A LÍNGUA COMO FERRAMENTA DE RESISTÊNCIA EM MULHERES DE CINZAS}

A obra Mulheres de Cinzas, primeiro livro da trilogia As Areias do Imperador faz parte do conjunto que o escritor Mia Couto iniciou em 2015. É um romance histórico, narrado por uma personagem feminina pertencente a uma das tribos da região e é entremeada pelas cartas de um sargento que vem para a cidade e se corresponde com seu oficial em Portugal, dando informações das atividades na aldeia de Nkokolani. O autor apresenta uma jovem africana e um sargento português, cuja relação vai além da estritamente profissional, para falar sobre a guerra que arruinou o sul de Moçambique no fim do século XIX.

Ambas as narrativas analisadas, Americanah e Mulheres de Cinzas, retratam a mulher sob dois vieses. Nesta narrativa, a personagem principal é Imani, uma jovem de 15 anos que, por ter aprendido a língua do europeu na escola, no caso, o português de Portugal, será intérprete do sargento português Germano de Melo. Imani é da tribo dos VaChopi, uma das poucas tribos que se opuseram à invasão de Ngungunyane, último dos líderes do Estado de Gaza. Por ser mulher e por estar envolvida com um militar, Imani sabe que precisa ficar invisível, porque num país em que a guerra dos homens assombra constantemente, ser mulher é sempre muito mais arriscado, e assim a simbologia das cinzas toma sua significação, pois a personagem precisa tornar-se invisível como se fosse constituída de cinzas para não ser percebida.

$\mathrm{Na}$ cultura moçambicana as representações se apresentam nas narrativas de modo bastante específico, pois com o Pós-colonialismo é possível perceber uma poética diversa daquela das literaturas das ex-colônias portuguesas em vários aspectos, como os registros de oralidade. Além de observar o que caracteriza a escrita de determinado escritor, é também importante a percepção de que essa produção constitui uma identidade da arte que evolui simultaneamente com a identidade de quem escreve.

\footnotetext{
7 "Google is fantastic. If people are interested, they can look something up. I remember thinking, 'I don't care if I'm published by a very tiny press and only ten people read it, but it will be the book I want to write.' And that's been my attitude from the beginning." (ADICHIE, 2014b).
} 
O escritor Mia Couto mistura na sua escrita a vida e a arte e assim desenvolve seu projeto de moçambicanidade. Sua literatura revela uma consciência evolutiva que segue na direção da cidadania, distante muitos anos luz do nacionalismo exercitado por muitos escritores no período colonial. Por isso, suas narrativas situam o sujeito em seu território, de modo que sua condição de indivíduo que vive nas margens, se vê refletida, analisada e até mesmo repensada sob novas perspectivas pela sociedade.

Essa nova visão da condição periférica do sujeito e sua posterior análise tanto estrutural quanto da sua conjuntura só ocorre porque a literatura pós-colonial se opõe terminantemente ao discurso do centro. A escrita mobiliza estratégias contra a discursividade hegemônica e escolhe trazer à baila a alteridade e a outridade possibilitando espaços para a manifestação de vozes até então silenciadas ou pouco ouvidas.

Esse aspecto pode ser observado na maneira como Mia Couto se utiliza da linguagem. O que o autor faz não é tornar a língua do colonizador uma língua africanizada, mas situá-la em territórios da África de modo que ela fique passível de influências e intercâmbios diversos. Em Mulheres de Cinzas, essa característica é percebida por meio da valorização das histórias, pequenas fábulas narradas dentro da grande história que é o romance. É percebida também, na oralidade, em alguns provérbios, lendas e crendices que se misturam a elementos em que a revelação das raízes culturais se fazem pela recuperação identitária dando a impressão de desafiar a língua portuguesa.

O hibridismo linguístico é um dos componentes bastante explorados pelos narradores contemporâneos, no período pós-colonial, além de contar com características significativas da textualidade africana. A língua usada pelo colonizador, da qual o escritor toma posse, é interposta de falas emblemáticas e específicas da nacionalidade, de modo que as raízes da cultura moçambicana transcendam o plano linguístico refletindo a cosmovisão de ser africano. Para o diálogo com as tradições, é estabelecido um modo próprio que se incorpora ao texto tornando-o intertextual, além da ocorrência de recriações sintáticas e lexicais. Leite (2003, p. 21), considera que esse fazer literário cria um novo campo capaz de tornar possível "coexistir, na maleabilidade da língua, a escrita com a oralidade, numa harmonia híbrida, mais ou menos imparável, que os textos literários nos deixam fruir". Assim, obtém-se como resultante desse procedimento os gêneros orais recuperados e a tradição revisitada criticamente.

A língua, como um dos instrumentos por meio dos quais os homens se expressam, é carregada por um discurso e apresenta como uma das suas características constantes o fato de ser ideológica. A linguagem e o pensamento são indissociáveis, para lembrar Fiorin (1988), e assim, o ser humano fala aquilo que pensa e por esse motivo, o discurso atua fazendo com que 
as representações ideológicas se materializem.

Mia Couto trabalha com a linguagem de forma que ela atue recuperando, o que Leite (2012) chama de mundividência moçambicana, ou seja, o modo de perceber e conceber o mundo sob o prisma da cultura africana. Neste caso da língua, por ela ser um refúgio de vozes com suas maneiras de pensar e por conter um poderio discursivo, tem um valor muito grande e um peso sem medida, cuja utilização pode permitir que grupos minoritários venham a ter espaço para ser percebidos e, possivelmente, ouvidos. As representações presentes na linguagem miacoutiana servem para explicar e justificar ordens sociais, conforme Fiorin (1988), o que se observa em Mulheres de Cinzas por meio da personagem protagonista Imani, por exemplo, que vê na língua um instrumento de igualdade.

Quando reinventa significantes e significados, Mia Couto faz uso de um léxico que alarga as margens da imaginação desconstruindo códigos e subvertendo a linearidade da língua. Nessa empreitada, transpõe as "fronteiras do interdito social e ideológico recorrendo para a reconversão do absurdo", conforme Mata (2003, p. 68), e utiliza estratégias que podem ser entendidas como de resistência, pois faz enfrentamento do real por meio de recursos como o insólito. Isso ocorre em Mulheres de Cinzas, quando pequenas histórias são contadas e passam a compor a tessitura da grande narrativa. Essas histórias, fábulas ou lendas, em geral, trazem a invenção como sua maior marca, como no caso da história narrada após a morte de Binguane. A narrativa contada pelos mais velhos não tinha relação com o que realmente ocorrera, mas mesmo assim, foi disseminada pela aldeia com toda as improbabilidades que só as lendas africanas possuem.

Horas depois da sua morte, já Binguane se convertera em lenda. À noite, quando as histórias podem ser contadas, os mais velhos narravam aos mais jovens a verdadeira razão da morte do grande guerreiro. E era assim a história: Era uma vez um rei que não acreditava na existência das nuvens. Defendia ele que as nuvens existiam apenas nos nossos olhos.

- Só acredito se puder tocar nelas.

Era o que ele dizia. E mandou que construíssem uma escada que fosse tão alta que lhe permitisse subir às mais nebulosas alturas. Demoraram anos a terminar a escadaria. Quando o chamaram, o rei olhou para o topo da construção e não conseguiu ver todos os degraus.

- Vou subir - declarou com firmeza.

Foi subindo, subindo e foi ficando mais e mais cansado. As andorinhas passavam por ele estranhando tão desajeitada companhia. Quando o rei já sofria de tonturas e de falta de ar, viu que estava rodeado de nuvens. Estendeu os braços para as tocar. Mas os dedos passaram por entre aquela espuma como se fossem luz atravessando água. E ele sorriu, feliz. Afinal, sempre tinha razão. Enquanto descia os degraus ia proclamando:

- Não lhes toquei. Não existem.

À medida que descia, reparou que ia ficando leve, cada vez mais leve. Já 
perto do chão teve mesmo que se segurar com firmeza. A mais ligeira brisa fazia-o drapejar como uma bandeira. Quando os pés tocaram o solo, o rei já se tinha convertido numa nuvem. Dele ficou a escada que conduz os descrentes à altura dos céus. (COUTO, 2015, p. 179-180).

$\mathrm{Na}$ narrativa, o autor aborda os discursos dos vários lados da história por meio da linguagem, dos dialetos, da pronúncia. Como intérprete do sargento Germano, Imani corrige, muitas vezes, a pronúncia que eles têm do idioma. Em conversa entre o cantineiro Sardinha e o sargento Germano de Melo, Imani, mesmo sem jeito, corrigiu-lhes a expressão dita: "Não são Vátuas, não existem Vátuas - ousei corrigir, no meu canto, num fio de voz tão suave que ninguém escutou" (COUTO, 2015, p. 67). Em outro momento, não corrigiu o significado do que diziam, mas a pronúncia.

- Não é 'Gungunhane'. Diz-se 'Ngungunyane' Os portugueses fitaram-me, surpresos. Não acreditavam que tivesse falado, ainda por cima para lhes corrigir o sotaque.

- O que é que disseste? - inquiriu, atónito, o Fragata.

- Deve-se pronunciar "Ngungunyane" - insisti com delicadeza. (COUTO, 2015, p. 69).

Ao fazer uma correção fonética, Imani deixa claro quem é que sabe falar aquela língua. Ela enfatiza que os portugueses devem falar aquela língua de forma correta, pois essa é uma maneira de respeitar a identidade do seu povo por meio da sua língua. Esse esmero para o militar, falar a língua adequadamente, tanto no campo lexical quanto no campo fonético, exprime o valor que Imani dá a isso, haja vista ela ter aprendido a falar a língua portuguesa como ninguém.

Ao empregar provérbios, ditos populares e frases feitas, Mia Couto faz com que o leitor se embrenhe na floresta mágica da cultura moçambicana e conheça cada vez mais da vastidão cultural das tribos e grupos étnicos daquele lugar. Não é possível apenas ler a narrativa, não se consegue molhar apenas os pés nas histórias dentro da grande história narrada; é preciso se banhar por completo, o corpo, o espírito, o entendimento, para compreender o universo vasto e diverso da moçambicanidade miacoutiana narrada por meio de provérbios, fábulas e lendas. Para Hamilton (1988, p. 05), o texto de Mia Couto recria a oralidade por meio de uma "língua literária sustentada por uma exuberante criatividade lexical e uma sintaxe que faz ponte entre a oralidade e a pura invenção, em que o contexto comunicativo, estético, possibilita a partilha da mensagem de ruptura" (HAMILTON, 1988, p. 05 apud LOPES, 2004, p. 306).

O uso de provérbios pode, por outro lado, exercer a função de desconstruir o conteúdo, 
sugerindo a desconstrução de papéis narrativos por meio do insólito produzindo um efeito que resulta no estranhamento do leitor.

\begin{abstract}
Os sinos voltaram a tocar e a coruja que vivia enclausurada nas ruínas esvoaçou sobre a minha cabeça. Fui pisando o chão atapetado de penas como se andasse sobre uma réstia de luar. Diz o provérbio que as plumas das corujas são tão leves que nunca chegam a tombar. Naquela noite, as plumas rodopiariam enlouquecidas e ascenderiam até se colarem às telhas. No teto, se converteriam em corpo e asa: nasceriam anjos. Nessa noite eu enlouqueceria como os cães. Os meus uivos arrepiariam a pele dos mais ousados. Como diz a mãe: para a minha loucura basta-me uma pequena porção de Lua. (COUTO, 2015, p. 119-120).
\end{abstract}

Há, além desses, outros mais que ilustram o que Hamilton diz acerca da exuberância na criatividade lexical e uma sintaxe mista entre invenção e oralidade. Mia Couto cria, também, inúmeras imagens poéticas que revestem o texto de singular beleza: "Os imperadores têm fome de terra e os soldados são bocas devorando nações" (COUTO, 2015, p. 15). "Os rios nascem no céu e cruzam a nossa alma como a chuva atravessa o céu. Escutando-os, não estamos tão sós" (COUTO, 2015, p. 63). "Imani diz que não devo matar os bichos. E tem uma teoria curiosa sobre os serviços que as aranhas prestam. Diz ela que as suas teias fecham as chagas do mundo. E que saram feridas que desconheço dentro de mim" (COUTO, 2015, p. 78). "- Precisamos amedrontar quem nos quer causar medo" (COUTO, 2015, p. 91). O autor dá um novo sentido para o texto literário metamorfoseando as palavras, dando-lhes conotações únicas, transformando a linguagem numa alomorfia criativa e muitas vezes inusitada, que ultrapassa o plano do discurso e revela as próprias crenças de quem escreve numa obra cujas narrativas se imbricam, e cujos tempos — do presente e da memória - se encontram e se entremeiam.

Esses eventos levam à percepção de que a singularização de cada personagem contribui para a construção de uma identidade coletiva resultante de uma cultura híbrida, e que o escritor cumpre uma função significativa ao mostrar esses traços culturais na sua escrita. De acordo com Mata (2003), trata-se

de um processo de recriação de desenredos verbais a que se segue a incorporação de saberes não apenas lingüísticos mas também de vozes tradicionais, do saber gnômico que o autor vai recolhendo e assimilando nas margens da nação para revitalizar a nação que se tem manifestado apenas pelo saber da letra.[...] Essa revitalização segue pela via de levedação em português de signos multiculturais transpostos para a fala narrativa em labirintos idiomáticos como forma de resistência ao aniquilamento da memória e da tradição. (MATA, 2003, p. 67-68). 
Entendo que as escolhas lexicais e semânticas de Mia Couto inseridas na narrativa são ideológicas e têm por intuito a reconstrução da história do povo de Nkokolani. Nessa construção literária moçambicana a linguagem é um fator de resistência que atua de infinitas formas, fazendo-se instrumento e receptáculo das manifestações culturais do país. A língua marca o posicionamento social do escritor por meio das personagens imbricadas na narrativa, pois alguns evidenciam seus interesses e valores nas escolhas linguísticas que fazem. $\mathrm{O}$ uso de determinado signo em vez de outro denota elementos da identidade do falante e aponta para o fato de a ser um fator identitário por meio do qual é possível entender ideologicamente os indivíduos.

Olhando por esse viés, percebo a pronúncia do sargento Germano de Melo quando diz o nome de Ngungunyane, que sempre o pronuncia Gungunhane, ou seja, a forma aportuguesada de dizer o nome do inimigo de Portugal. Nos capítulos em que Imani narra, o nome do Imperador de Gaza é grafado e pronunciado por ela e os seus de forma correta, - a não ser que a pessoa que fala é alguém que desconhece a pronúncia correta, - mas nos capítulos em que o sargento Germano escreve cartas para seu superior, a grafia e a pronúncia sempre aparecem de modo a dar impressão de ele não se importar com a pronúncia correta, ou não dar valor ao idioma. Enquanto Imani dominava a língua do colonizador, como o próprio Germano elogiou, ele não demonstra interesse em aprender adequadamente o idioma dos Chopes e diz ora Gungunhane ora Gugunhane sem maiores preocupações com a escrita correta.

As palavras presentes na narrativa são uma mescla do txitxope, língua dos Chopes e português, do sargento Germano de Melo. Há também, em alguns momentos, a presença do idioma shizulu ou xizulu, grafado na narrativa de ambas as formas, que é a língua dos ocupantes, falada por alguns soldados. A mãe de Imani, Chikazi Makwakwa, conhece essa língua por ter nascido e passado a infância em terras do sul. Chikazi foi uma mabuingela, "esses que caminham à frente para limparem o orvalho do capim" (COUTO, 2015, p. 21). Imani e os irmãos eram produto dessa mistura de histórias e culturas. Essas e muitas outras palavras, como timbissi, palavra zulu para hienas, se entremeiam à escrita miacoutiana e vão trazendo para a narrativa seus significados a todo o tempo.

Há outros momentos em que a narração traz a palavra no idioma Chope e, logo em seguida, apresenta seu significado, como em: "Deram-lhe um nome zulu e essa escolha já dizia do seu estranho fascínio pelos invasores VaNguni. Dubula quer dizer "disparo de arma"." (COUTO, 2015, p. 49); "era uma Noyi, uma feiticeira" (COUTO, 2015, p. 23); 
"fabrica-se o moya, a alma" (COUTO, 2015, p. 15); "Esse duende — esse txigono, como nós dizemos - assaltava as casas e invadia os currais, deixando um rasto de enorme alarido" (COUTO, 2015, p. 248); "Aquele era o altar da família, o nosso digandelo" (COUTO, 2015, p. 120). Essa insistência de Imani no registro dos signos da língua materna ao narrar transmite ao ato narrativo um caráter ideológico, pois reforça a tessitura de um sujeito que considera o valor da língua que fala em igualdade com o idioma do colonizador. Ao dar importância ao registro e à utilização da sua língua, em vez de descartá-la e assimilar a do dominante, a personagem faz uma inversão da realidade, e esse fator caracteriza ideologia (FIORIN, 1988, p. 29).

Esses fenômenos evidenciam um hibridismo linguístico que caracteriza a textualidade do escritor moçambicano e essa hibridação ocorre devido a maleabilidade da língua, que permite a coexistência da escrita e da oralidade, segundo Leite (2012). A criação de neologismos com o nome do imperador Ngungunyane feita pelo sargento na pronúncia aportuguesada do nome se evidencia na diferença entre os elementos fonéticos da língua portuguesa e da língua chope.

Esse hibridismo é uma peculiaridade significativa da literatura africana em língua portuguesa, conforme Leite (2003), que se reflete na narrativa tanto pela forma como é grafada quanto pelos elementos de mais de uma língua presentes no decorrer da história, transportando para o texto literário o retrato de um território em que coexistem mais de um idioma, e que a duplicidade acontece nas identidades das personagens bem como nas narrativas que comportam outras dentro de si e carregam a história de dois mundos na sua tessitura.

\section{CONSIDERAÇÕES FINAIS}

Com base no estudo da escritura das narrativas e dos traços que as marcam conclui-se que a escritura apresenta traços de resistência essenciais para a subversão dos discursos hegemônicos de modo a trazer à tona padrões conceituais que vão além do pertencimento cultural como tradicionalmente imaginado. Por meio da resistência das personagens das obras, a escritura dupla que permeia a escrita de Adichie e Couto se mostra trazendo uma reconceitualização da cultura incorporada a um sentimento de ambivalência, que a desterritorialização gera engendrando culturas híbridas. Essa escritura múltipla instrumentaliza a linguagem utilizada pela autora e pelo autor, de modo a torná-la ferramenta de poder. 
O posicionamento de Adichie e Couto quanto a esse tema torna-os capaz de elevar as personagens da condição de subalternidade para a resistência no projeto ficcional. Além disso, percebi que a resistência ocorre nos eventos narrados, de forma que os indivíduos que vivem uma condição de objetificação pelo colonizador conseguem contradizer esse sistema opressor se subjetificando e tomando para si sua independência.

O estudo dos elementos da tessitura narrativa dá mostras da escrita literária como um exercício crítico e criativo consciente de Adichie e Couto. Ambos fazem aparecer, na linguagem das personagens, expressões próprias, palavras ou frases da língua de tribos nativas, componentes do enredo. Essa linguagem traz uma mescla cultural permeada por subjetividades e identidades diversas formadas pelas e com as diferenças, indiciando o sujeito nigeriano e moçambicano híbrido, visto que os processos de hibridação continuam acontecendo devido à apropriação da cultura do outro. Como resultado, os modos de narrar de Adichie e Couto evidenciam processos de hibridação em que uma língua, a do negro, do colonizado, se enleia a outra, se infiltra na outra passando a ocupar um espaço que é seu.

\section{REFERÊNCIAS}

ADICHIE, Chimamanda Ngozi. Americanah. Trad. Julia Romeu. São Paulo: Companhia das Letras, 2014.

AFONSO, Maria Fernanda. O conto moçambicano, escritas pós-coloniais. Lisboa: Caminho, 2004.

BHABHA, Homi K. O local da cultura. Belo Horizonte: Editora UFMG, (Coleção Humanitas), 2005.

CHAN, Mauricio Aparecido. Leituras sobre a Guerra de Biafra (1967-1970) As Versões do Conflito nos Textos de História e Literatura. Monografia. Universidade de Brasília. 2007.

COUTO, Mia. Mulheres de Cinzas: as areias do imperador: uma trilogia moçambicana, Livro 1. $1^{a}$ ed. São Paulo: Companhia das Letras, 2015.

FIORIN, José Luiz. Linguagem e ideologia. São Paulo: Ática, 1988.

HAMILTON, Russel. Dinâmica da oralidade fica estática na escrita. Domingo. Maputo, 1988. In: LOPES. José de Sousa Miguel. Cultura acústica e letramento em Moçambique: em busca de fundamentos antropológicos para uma educação intercultural. Educ. São Paulo. 2004.

LEITE, Ana Mafalda. Literaturas africanas e formulações pós-coloniais. Lisboa: Colibri, 2003. 
Oralidades \& escritas pós-coloniais: estudos sobre literaturas africanas. Rio de Janeiro: EdUERJ, 2012.

MATA, Inocência. A condição pós-colonial das literaturas de língua portuguesa: algumas diferenças e convergências e muitos lugares-comuns. In: LEÃO, Ângela Vaz (org.). Contatos e consonâncias: literaturas africanas de língua portuguesa. Belo Horizonte: PUC Minas, 2003.

\section{SITES CONSULTADOS}

ADICHIE, Chimamanda Ngozi. 'NBCC Fiction Finalist Chimamanda Ngozi Adichie in Conversation with Brooke Obie', Entrevista. 2014a. Disponível em: http://bookcritics.org/blog/archive/nbcc-fiction-finalist-chimamanda-ngozi-adichie-inconversation-with-brooke. Último acesso em: 04 de janeiro de 2020.

IFEJIKA, Nkem. Identity 2016: Why I stopped mispronouncing my Igbo name. Magazine. BBC World Service. 27 April 2016. Disponível em: http://www.bbc.com/news/magazine$\underline{36139908}$ Último acesso em: 02 de jan. de 2020.

RELATÓRIO, alternativo diante do Comité de Eliminação da discriminação contra as mulheres. Direitos de mulher no Moçambique - Dever de terminar práticas ilegais 2007, Disponível em: https://www.fidh.org/IMG/pdf/mz042008p.pdf. Último acesso em: $07 \mathrm{de}$ janeiro de 2020.

Recebido: $21 / 08 / 2019$

Aprovado: 16/04/2020 